\title{
Correction to: Efficacy and safety of the long-acting C5 inhibitor ravulizumab in patients with atypical hemolytic uremic syndrome triggered by pregnancy: a subgroup analysis
}

Anja Gäckler ${ }^{1 *}$, Ulf Schönermarck², Vladimir Dobronravov ${ }^{3}$, Gaetano La Manna ${ }^{4}$, Andrew Denker ${ }^{5}$, Peng Liư , Maria Vinogradova ${ }^{6}$, Sung-Soo Yoon ${ }^{7}$ and Manuel Praga ${ }^{8}$

Correction to: BMC Nephrol (2021) 22:5

https://doi.org/10.1186/s12882-020-02190-0

Following publication of the original article [1], authors informed us that the PLS file was to be included in the supplementary information.

The original article [1] has been corrected.

\begin{abstract}
Author details
'Department of Nephrology, University Hospital Essen, University

Duisburg-Essen, Essen, Germany. ${ }^{2}$ Medizinische Klinik IV, LMU Klinikum, LMU,

Munich, Germany. ${ }^{3}$ Pavlov University, Research Institute of Nephrology, St.

Petersburg, Russia. ${ }^{4}$ Department of Experimental Diagnostic and Specialty

Medicine (DIMES), Nephrology, Dialysis and Renal Transplant Unit, St. Orsola Hospital, University of Bologna, Bologna, Italy. ${ }^{5}$ Alexion Pharmaceuticals, Inc., Boston, USA. ${ }^{6}$ National Medical Research Centre for Obstetrics and Gynecology, Moscow, Russia. ${ }^{7}$ Seoul National University Hospital, Seoul, Republic of Korea. ${ }^{8}$ Instituto de Investigación Hospital Universitario 12 de Octubre i+12, Madrid, Spain.
\end{abstract}

Published online: 02 February 2021

\section{Reference}

1. Gäckler A, et al. Efficacy and safety of the long-acting C5 inhibitor

ravulizumab in patients with atypical hemolytic uremic syndrome triggered by pregnancy: a subgroup analysis. BMC Nephrol. 2021;22:5 https:/doi.org/ 10.1186/s12882-020-02190-0.

The original article can be found online at https://doi.org/10.1186/s12882020-02190-0.

* Correspondence: Anja.Gaeckler@uk-essen.de

'Department of Nephrology, University Hospital Essen, University Duisburg-Essen, Essen, Germany

Full list of author information is available at the end of the article

(c) The Author(s). 2021 Open Access This article is licensed under a Creative Commons Attribution 4.0 International License, which permits use, sharing, adaptation, distribution and reproduction in any medium or format, as long as you give appropriate credit to the original author(s) and the source, provide a link to the Creative Commons licence, and indicate if changes were made. The images or other third party material in this article are included in the article's Creative Commons licence, unless indicated otherwise in a credit line to the material. If material is not included in the article's Creative Commons licence and your intended use is not permitted by statutory regulation or exceeds the permitted use, you will need to obtain permission directly from the copyright holder. To view a copy of this licence, visit http://creativecommons.org/licenses/by/4.0/ The Creative Commons Public Domain Dedication waiver (http://creativecommons.org/publicdomain/zero/1.0/) applies to the data made available in this article, unless otherwise stated in a credit line to the data. 